\title{
Neural Control of the Sphincter of Oddi
}

\author{
A PHYSIOLOGICAL ROLE OF 5-HYDROXYTRYPTAMINE IN THE \\ REGULATION OF BASAL SPHINCTER OF ODDI MOTOR
} ACTIVITY IN THE CAT

\author{
Jose Behar and Piero Biancani, Department of Medicine, Division of \\ Gastroenterology, Rhode Island Hospital and Brown University, \\ Providence, Rhode Island 02902
}

A B S T R A C T The effect of 5-hydroxytryptamine (5$\mathrm{HT}$ ) on the sphincter of Oddi (SO) was studied in the cat. The SO had two motor responses to 5-HT: the most common was an initial contraction followed by a more prolonged relaxation, and the other was an exclusive relaxation. Tetrodotoxin did not impair the magnitude of the net contraction induced by $5-\mathrm{HT}$, but it completely blocked the relaxation. Methysergide partially inhibited the SO contraction in response to submaximal doses of $5-\mathrm{HT}(5-20 \mu \mathrm{g} / \mathrm{kg})$. Atropine decreased the SO excitatory response to all doses of 5HT. The combination of atropine and methysergide completely antagonized the 5-HT excitatory effect, which changed the SO biphasic response to an exclusive relaxation. After tetrodotoxin, the effect of 5-HT was almost completely antagonized by methysergide alone. The SO contraction and relaxation caused by 5-HT were almost completely blocked by 5 -HT tachyphylaxis. In contrast, a 5-HT depletion with reserpine enhanced the sensitivity of the SO to 5-HT, responding to doses a thousand times smaller than in control animals. Hexamethonium, phentolamine, propranolol, and 5-methoxy- $\mathrm{N}, \mathrm{N}$-dimethyltryptamine did not antagonize the 5-HT-induced contraction or relaxation. These findings indicate that 5-HT caused SO contraction by stimulating postganglionic cholinergic neurons and the smooth muscle directly and caused relaxation by stimulating postganglionic, noncholinergic, nonadrenergic inhibitory neurons. 5-HT blockade or depletion resulted in a significant reduction in basal tonic

Address all correspondence to Dr. Behar, Division of Gastroenterology, Rhode Island Hospital, 593 Eddy Street, Providence, RI 02902.

Received for publication 7 May 1982 and in revised form 15 April 1983. pressures and in the amplitude of phasic contractions, which suggested that serotonergic neurons may play a physiologic role in the regulation of basal SO motor activity.

\section{INTRODUCTION}

There is increasing evidence that 5-hydroxytryptamine $(5-\mathrm{HT})^{1}$ may play a physiological role in the control of the gastrointestinal motor function $(1,2)$. This amine has met most of the criteria required of a neurotransmitter within the enteric neural system and may participate in the regulation of interneuronal functions (3). 5-HT has been found in myenteric neurons (4) and its concentration is estimated to be of the same magnitude there as in the brain (5). 5-HT can be released by neural stimulation (6) and in many ways, it mimics the effect of nerve stimulation $(7,8)$. Furthermore, 5-HT tachyphylaxis blocks the effect of nerve stimulation (9).

Because of the potential physiological importance of 5-HT, we have studied its effect, mechanism of action, and contribution to the maintenance of basal sphincter of Oddi (SO) motor activity.

\section{METHODS}

68 adult cats of both sexes that weighed $2-5 \mathrm{~kg}$ were studied. The animals were anesthetized with intramuscular Ketamine hydrochloride ( $30 \mathrm{mg} / \mathrm{kg}$ body weight) and maintained with smaller doses of $5-15 \mathrm{mg} / \mathrm{kg}$ as needed. They were studied in the supine position with a constant slow intravenous infusion of Ringer's solution with 5\% dextrose. Respiration was

\footnotetext{
${ }^{1}$ Abbreviations used in this paper: 5-HT, 5-hydroxytryptamine; 5-Me-DMT, 5-methoxy-N,N-dimethyltryptamine; OP-CCK, octapeptide of cholecystokinin; SO, sphincter of Oddi; TTX, tetrodotoxin.
} 
assisted and controlled by a ventilator (Harvard Apparatus Co., Inc., Model 607, South Natick, MA) through a tracheostomy tube. Arterial blood pressure was continuously monitored through a cannula placed in the femoral artery. After a midline abdominal incision, the gallbladder and biliary tree were identified. The SO pressures were measured using a method previously described (10). A constantly perfused $(0.3 \mathrm{ml} / \mathrm{min})$ open-tipped catheter $($ o.d. $=1.57 \mathrm{~mm})$ was used. This catheter was placed in the common bile duct, advanced until resistance was encountered, and then withdrawn $1 \mathrm{~mm}$. At this point, it was anchored with a tight loop of suture silk using the purse-string technique. The catheter was large enough to occupy the entire lumen of the common bile duct and the tight loop prevented retrograde flow. Pressures thus recorded were a reflection of the SO resistance to flow. This method has been previously validated as reliable and reproducible for measuring SO pressures (10). Simultaneous measurements of duodenal and SO motor activity indicate that there is a tonic pressure gradient of $16.4 \pm 3.2$ $\mathrm{mmHg}$ (12 experiments) and that the phasic contractions in the duodenum and SO are different in the timing, frequency, and amplitude. Occasionally, the timing or frequency was the same, but the amplitude of the phasic contractions was different. The frequency and amplitude of phasic contractions were always different from the respiratory rate which was clearly indicated by the gallbladder pressure recordings. Furthermore, pressure recordings that were obtained in the common bile duct by its side opening pressure sensor, which had been introduced through an incision in the duct or through the duodenum and ampulla of Vater, failed to measure any tonic pressures or phasic activity.

Gastrointestinal hormones and drugs, except for tetrodotoxin (TTX) and reserpine, were given intravenously in bolus doses over a 30 -s period. The pharmacological agents used were: synthetic octapeptide of cholecystokinin (OP-CCK), $100 \mathrm{ng} / \mathrm{kg}$ (E. R. Squibb \& Sons, Princeton, NJ); TTX, 36 $\mu \mathrm{g} / \mathrm{kg}$ was given in a slow infusion over a 20-30 min period (Calbiochem-Behring Corp., La Jolla, CA); reserpine, $3 \mathrm{mg}$ / $\mathrm{kg}$ i.p. 48 and $24 \mathrm{~h}$ before the experiments (Ciba-Geigy Co., Summit, NJ); atropine sulfate, $30 \mu \mathrm{g} / \mathrm{kg}$ (Eli Lilly, and Co., Indianapolis, IN); hexamethonium hydrochloride, 20-40 $\mathrm{mg} / \mathrm{kg}$ (City Chemical Corp., NY); phentolamine, 1-1.5 mg/ kg (Ciba Pharmaceutical Co., Seymour, IN); propranolol, $1.5-2.0 \mathrm{mg} / \mathrm{kg}$ (Ayerst Laboratories, NY); 5-HT, 0.005-1000 $\mu \mathrm{g} / \mathrm{kg}$ (Calbiochem-Behring Corp.); bethanechol, $20 \mu \mathrm{g} / \mathrm{kg}$ (Merck, Sharp \& Dohme Div., Montreal, Canada); phenylephrine, $50 \mu \mathrm{g} / \mathrm{kg}$ (Robinson Laboratory, Inc., San Francisco, CA); isoproterenol, $4 \mu \mathrm{g} / \mathrm{kg}$ (Winthrop Laboratories Inc., NY); nicotine, $100 \mu \mathrm{g} / \mathrm{kg}$ (Eastman Kodak Corp., Rochester, NY); tyramine, $100 \mu / \mathrm{kg}$ (Aldrich Chemical Co., Inc., Metuchen, NJ); methysergide (Sandoz Inc., Pharmaceutical Div., East Hanover, $\mathrm{NJ}$ ) that was given initially as a bolus followed 10 min later by a constant infusion; and 5-methoxy$N, N$-dimethyltryptamine (5-Me-DMT, Sigma Chemical Co., St. Louis, MO) that was also given as a bolus dose followed by a constant infusion. The doses of the agonists were selected by performing dose-response studies. The antagonist dose used was selected by determining the dose that blocked the maximal dose of its respective agonist.

Tonic SO pressures were measured as mean end-expiratory pressures over a 5 -min period immediately before and 30 min after the administration of a pharmacological antagonist. SO phasic contractions were measured as a mean amplitude of the contractions above tonic pressures over a 5min period immediately before and $30 \mathrm{~min}$ after the administration of a pharmacological antagonist. The effect of short-acting pharmacological agonists or gastrointestinal hormones was determined at the peak or nadir of pressures observed within a 10 -min period after the administration. Paired and unpaired Student's $t$ tests were used for statistical analysis.

\section{RESULTS}

SO response to exogenous 5-HT. The SO responded to $5-\mathrm{HT}(5-80 \mu \mathrm{g} / \mathrm{kg})$ with two major patterns (Fig. 1). The most common response was one of initial and brief contraction, which was followed by a more prolonged relaxation. The SO contraction was characterized by an increase in tonic pressures and the amplitude and frequency of phasic contractions. Relaxation was characterized by total abolition of phasic contractions and a slight decrease in tonic pressures. A less frequent response was exclusive relaxation ( $\sim 6 \%$ of the animals tested). The minimal dose that had a consistent excitatory or inhibitory effect on the SO was $5 \mu \mathrm{g} / \mathrm{kg}$. Maximal SO contraction was obtained with 5-HT doses of $40-80 \mu \mathrm{g} / \mathrm{kg}$. Maximal relaxation occurred with doses of $20 \mu \mathrm{g} / \mathrm{kg}$ (Fig. 2).

Pharmacological analysis of the 5-HT effect. The mechanisms of the 5-HT-induced SO contraction and relaxation were studied by pharmacological manipulation. The effect of 5-HT on the SO was assessed after neural blockade with TTX (Fig. 3). Completeness of the neural block was tested with OP-CCK (100 ng/ $\mathrm{kg}$ ), which caused SO relaxation in control conditions and contraction after TTX (10). In selected experiments, SO denervation was also demonstrated with other stimuli, such as cervical vagal stimulation or direct intramural stimulation $(1 \mathrm{~ms}, 10 \mathrm{~Hz}$, and $10 \mathrm{~V})$ and intravenous edrophonium $(100 \mu \mathrm{g} / \mathrm{kg})$. After TTX, the SO did not relax or contract in response to these stimuli.

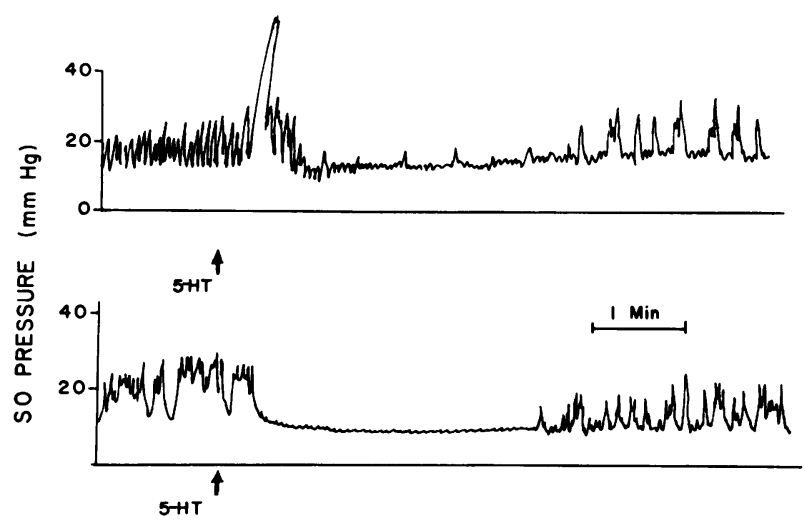

Figure 1 Manometric tracings illustrating the effect of 5HT. The upper panel shows the most common SO response of a marked but brief excitation followed by inhibition. The lower panel shows the less common response of exclusive inhibition. 


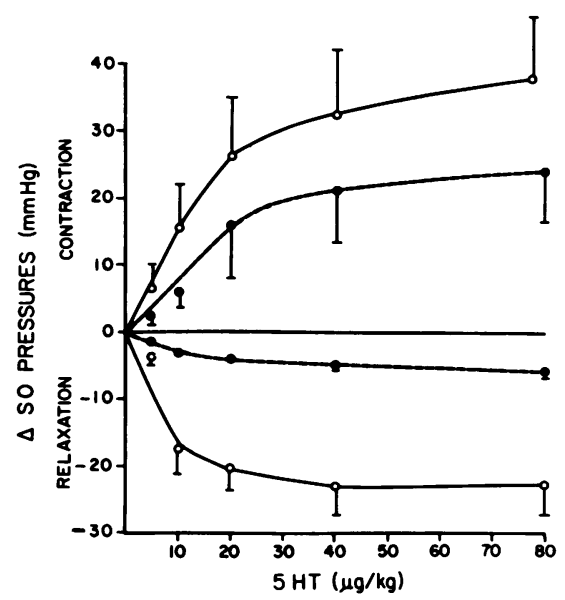

Figure 2 Dose-response studies with 5-HT. Values are mean $\pm S E$ of 18 animals. $O$, phasic; $\bullet$, tonic.

The excitatory effect of 5-HT was unaltered by TTX. The SO contraction in response to increasing doses of 5-HT after TTX was not different from control $(P$ $<0.50)$. In contrast, SO relaxation was antagonized completely by TTX with all doses of 5-HT used ( $P$ $<0.01$ ). The excitatory effect of 5-HT was blocked partially by methysergide infusion or by atropine, and it was blocked completely by a combination of atropine and methysergide infusion. Methysergide caused a shift of the 5-HT dose-response curve to the right (Fig. 4). The pressure increase in response to $5-\mathrm{HT}$ was significantly lower at submaximal doses of 5,10 , and $20 \mu \mathrm{g} / \mathrm{kg}(P<0.05)$; there was no difference from

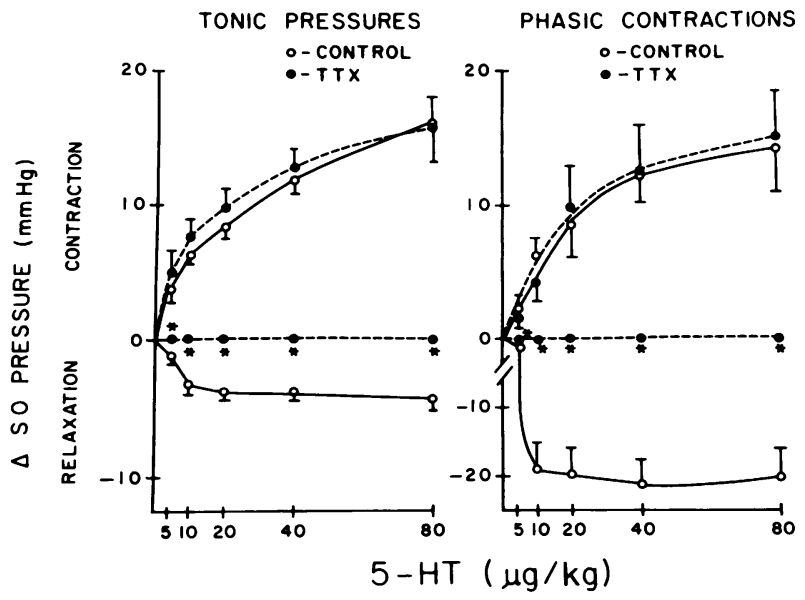

Figure 3 Effect of TTX on the SO response to 5-HT. Values are means $\pm S E$. The $S O$ contraction was studied in seven animals, whereas the SO relaxation was studied in six animals. Asterisks indicate that the $\Delta \mathrm{SO}$ response is significantly different from control values $(P<0.01)$.

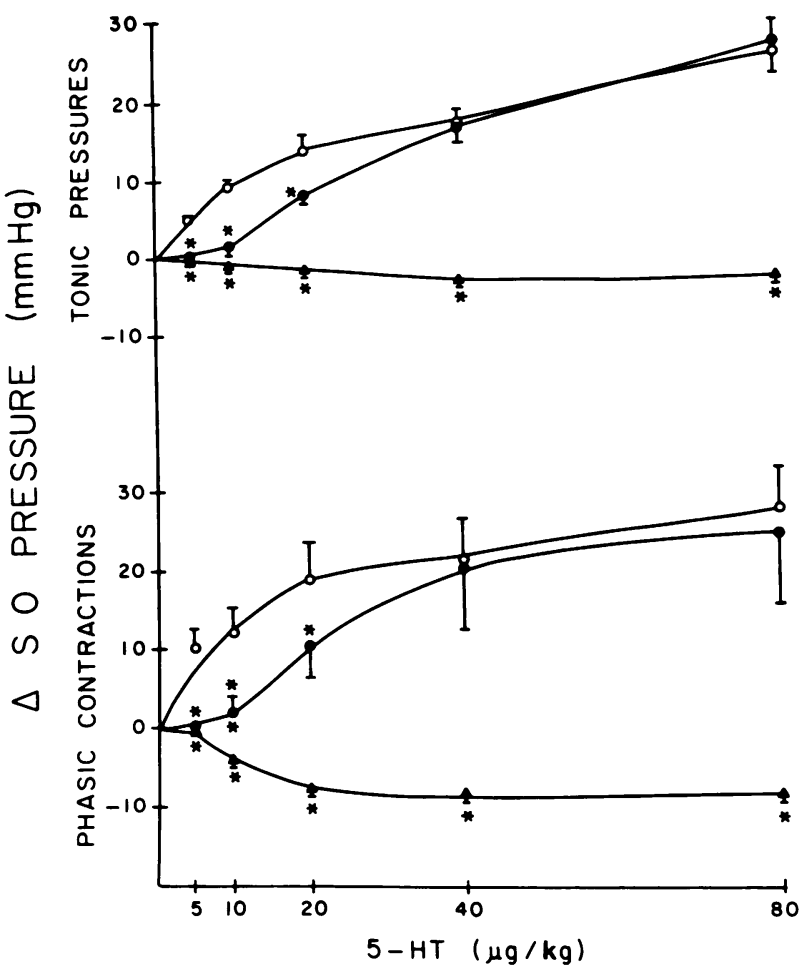

Figure 4 Dose-response studies with 5-HT before and after IV methysergide infusion, and after a combination of methysergide with atropine. Values are means $\pm S E$ of five animals. Methysergide infusion decreased the $\mathrm{SO}$ contraction induced by $5-\mathrm{HT}$ at doses of 5,10 , and $20 \mu \mathrm{g} / \mathrm{g}(P<0.05)$. The addition of atropine blocked the SO contraction completely at all doses studied $(P<0.01)$. Statistical significance is indicated by an asterisk. $O$, control; $\bullet$, methysergide; $\Delta$, methysergide and atropine.

controls with 5-HT doses of $40-80 \mu \mathrm{g} / \mathrm{kg}(P>0.05)$. In contrast, atropine reduced the pressure increase in response to all 5 -HT doses from 5 to $80 \mu \mathrm{g} / \mathrm{kg}(P$ $<0.001$, Fig. 5).

The combination of atropine and methysergide infusion blocked the SO contraction completely in response to each 5-HT dose $(P<0.01$, Fig. 4$)$. The combined effect of these two antagonists resulted in a change of the biphasic SO response to an exclusive relaxation with all 5-HT doses. The SO relaxation after these two antagonists was of the same magnitude but of longer duration than in the control period $(P$ $>0.05$ ).

To determine the site of the antagonistic effect of methysergide to 5-HT, a bolus injection of methysergide, which was followed by a constant infusion, was given after neural blockade with TTX (Fig. 6). Prior to TTX, the SO response to 5-HT was biphasic with an initial contraction, which was followed by relaxation. An exclusive SO contraction in response to 


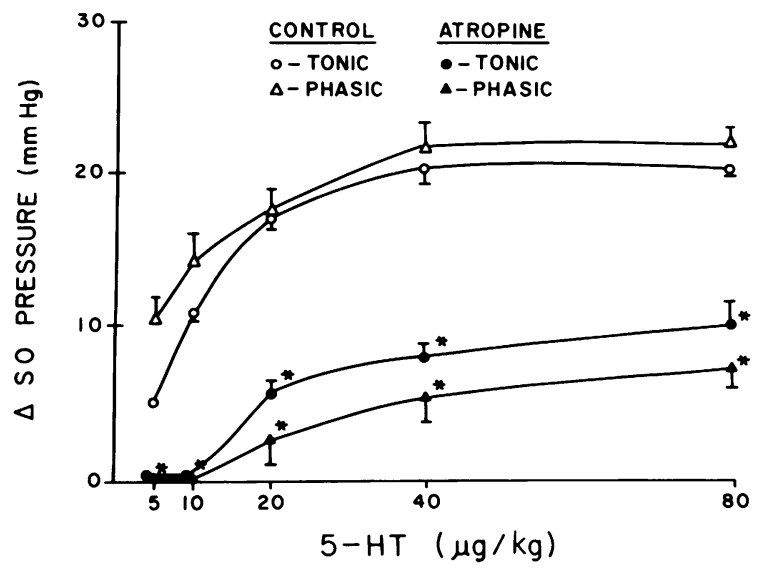

Figure 5 Effect of atropine on the SO response to 5-HT. Values are means $\pm S E$ of five experiments. Asterisk indicates that $\Delta$ SO pressures after atropine are significantly different from control $(P<0.01)$.

5-HT was observed after TTX. The magnitude of the contraction did not differ before and after TTX $(P$ $>0.05$, Fig. 6). After TTX, a methysergide infusion markedly shifted the 5-HT dose-response curve to the right, which resulted in an almost complete blockade of the excitatory effect $(P<0.01)$.

The specificity of the excitatory and inhibitory actions of 5-HT was tested by inducing tachyphylaxis with large doses of $5-\mathrm{HT}(1 \mathrm{mg} / \mathrm{kg})$. These large doses of 5-HT caused auto-inhibition. The auto-inhibition antagonized the SO contraction $(P<0.02)$ and relaxation $(P<0.05)$, which were induced by a maximal dose of 5-HT $(80 \mu \mathrm{g} / \mathrm{kg})$, even after a 30 -min interval (Fig. 7). The SO, however, could respond to betha-

TONIC PRESSURES

PHASIC CONTRACTIONS

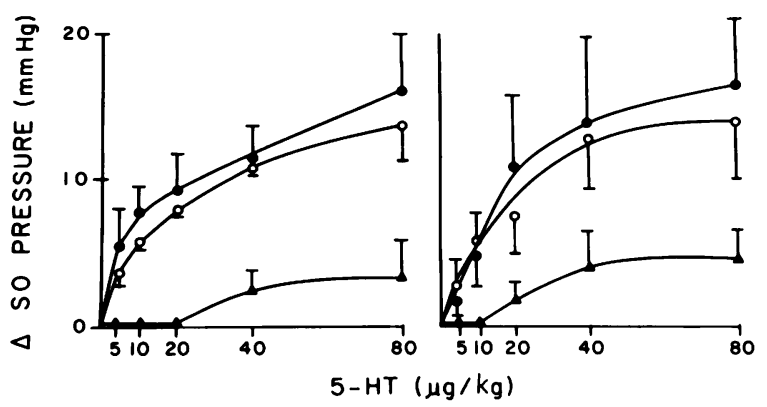

FIGURE 6 Effect of 5-HT dose-response study in control conditions (O), after TTX (๑), and after TTX and methysergide infusion $(\Delta)$. Values are means $\pm S E$ of five animals. Methysergide infusion decreased the $\Delta \mathrm{SO}$ pressure response to all doses of 5-HT after TTX $(P<0.01)$.

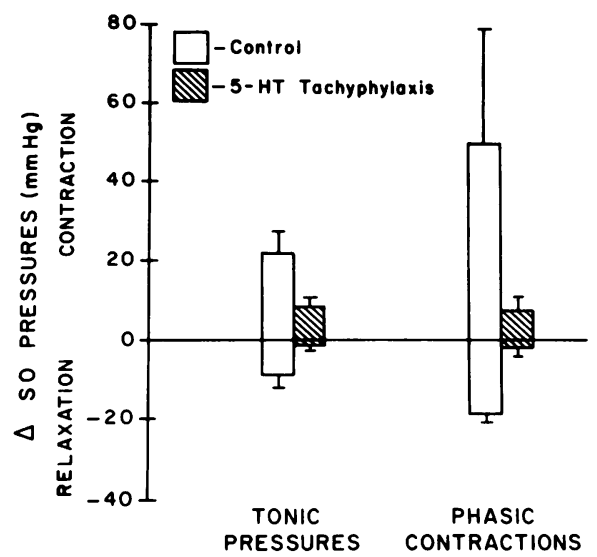

Figure 7 SO motor response to a maximal dose of 5-HT $(80 \mu \mathrm{g} / \mathrm{kg})$ before and after $5-\mathrm{HT}$ tachyphylaxis induced with $1 \mathrm{mg} / \mathrm{kg}$. Values are means $\pm S E$ of six animals. 5-HT tachyphylaxis markedly reduced the SO contraction ( $P$ $<0.02$ ) and relaxation induced by $5-\mathrm{HT}$.

nechol $(20 \mu \mathrm{g} / \mathrm{kg})$ with contraction and to isoproterenol $(4 \mu \mathrm{g} / \mathrm{kg})$ with relaxation.

The mechanism of action of 5-HT was further investigated by obtaining dose-response curves before and after treatment with the ganglionic blocker, hexamethonium, and the alpha adrenergic receptor blocker, phentolamine (Tables I, A and B). Neither antagonist had any effect on the SO contraction, which was induced by each 5 -HT dose $(P>0.05)$.

Treatment with reserpine, 48 and $24 \mathrm{~h}$ before the experiments, increased the sensitivity of the SO to the excitatory effects of 5-HT (Fig. 8). Adequate catecholamine depletion was tested with tyramine which, in control experiments, caused a prolonged contraction characterized by an increase in tonic pressures and in the amplitude and frequency of phasic contractions. Catecholamine-depleted animals, however, did not respond to tyramine at all. Reserpine treatment shifted the 5-HT dose-response curve to the left. The lowest dose of 5-HT that caused SO contraction in control animals was $5 \mu \mathrm{g} / \mathrm{kg}$, whereas reserpinized animals responded to doses of $0.5,0.05$, and $0.005 \mu \mathrm{g} / \mathrm{kg}$, which caused contraction exclusively. After reserpine, the SO contraction was significantly higher for submaximal doses of 5-HT $(P<0.01)$.

The 5-HT-induced relaxation was not affected by any antagonist used, except TTX $(P<0.001$, Fig. 3$)$ and 5-HT tachyphylaxis $(P<0.05$, Fig. 7$)$. It was not antagonized by hexamethonium $(P>0.05)$ or by beta adrenergic blockade with propranolol $(P<0.50, \mathrm{Ta}-$ bles I, A and B). The serotonin analogue 5-Me-DMT (Fig. 9) also failed to block the 5-HT-induced relaxation; after 5-Me-DMT, the SO inhibition actually was of greater magnitude $(P<0.05)$ because 5 -Me-DMT 
TABLE IA

Effect of Pharmacological Antagonists on the SO Tonic Pressure Response to 5-HT

\begin{tabular}{lcccccc}
\hline & & \multicolumn{5}{c}{$5-\mathrm{HT}(\mu \mathrm{g} / \mathrm{kg})$} \\
\cline { 3 - 7 } & $n$ & 5 & 10 & 20 & 40 & 80 \\
\hline Control & \multirow{2}{*}{\begin{tabular}{c}
$n$ \\
\cline { 3 - 6 }
\end{tabular}} & $6.8 \pm 3.4^{\circ}$ & $10.2 \pm 3.8$ & $14.0 \pm 4.3$ & $19.0 \pm 5.1$ & $21.8 \pm 4.4$ \\
Hexamethonium & 6 & $5.8 \pm 2.5$ & $10.0 \pm 2.1$ & $11.8 \pm 2.1$ & $15.8 \pm 3.6$ & $21.2 \pm 4.9$ \\
Control & & $5.6 \pm 2.3$ & $13.2 \pm 3.9$ & $32.0 \pm 17.4$ & $36.8 \pm 16.0$ & $39.8 \pm 16.0$ \\
Phentolaminet & 5 & $4.0 \pm 2.6$ & $12.6 \pm 4.1$ & $30.0 \pm 13.0$ & $35.4 \pm 14.0$ & $45.0 \pm 17.0$ \\
Control & & $-1.3 \pm 0.4$ & $-2.8 \pm 0.5$ & $-3.5 \pm 0.5$ & $-3.7 \pm 0.6$ & $-5.2 \pm 1.1$ \\
Propranololt & 6 & $-0.7 \pm 0.7$ & $-3.3 \pm 0.6$ & $-6.0 \pm 1.2$ & $-6.5 \pm 1.1$ & $-6.7 \pm 1.2$ \\
\hline
\end{tabular}

- Values are means $\pm \mathrm{SE}$ of $\Delta$ tonic pressures in $\mathrm{mmHg}$ before and after antagonists.

$\$$ Paired Student's $t$ test comparing $\Delta$ pressure induced by 5-HT in the control state and after treatment were not significantly different. The symbol $(-)$ refers to $\Delta$ SO relaxation in response to 5 -HT.

increased basal tonic pressures and the amplitude of phasic contractions.

SO response to pharmacological antagonists. Several pharmacological antagonists influenced basal SO tonic pressures and the amplitude of phasic contractions (Table II). At doses that caused complete blockade of axonal conduction, TTX induced a significant increase in tonic pressures $(P<0.004)$ and in the amplitude of phasic contractions $(P<0.001)$. In contrast, methysergide infusion or atropine caused a slight decrease in the amplitude of phasic contractions $(P$ $<0.05)$, but did not affect basal tonic pressures $(P$ $<0.10$ ). The combination of atropine and methysergide, however, caused a significant reduction in basal SO motor activity with a decrease in both tonic pres- sures and the amplitude of phasic contractions ( $P$ $<0.05$ ). Furthermore, 5-HT tachyphylaxis with 5-HT doses that caused auto-inhibition of a maximal 5-HT dose $(80 \mu \mathrm{g} / \mathrm{kg})$ produced a significant reduction in tonic pressures $(P<0.001)$ and the amplitude of phasic contractions $(P<0.05)$. This reduction of SO motor activity by 5 -HT tachyphylaxis was reversed by TTX, which restored tonic pressures and the amplitude of phasic contractions $(P<0.001)$ to pretachyphylaxis levels. Reserpine caused a significant reduction in basal tonic pressures and the amplitude of phasic contractions when compared with a control group $(P<0.001)$. All other antagonists used did not affect either tonic pressures or the amplitude of phasic contractions $(\boldsymbol{P}$ $<0.10)$.

TABLE IB

Effect of Pharmacological Antagonists on the SO Phasic Contractions in Response to 5-HT

\begin{tabular}{|c|c|c|c|c|c|c|}
\hline & \multirow[b]{2}{*}{$n$} & \multicolumn{5}{|c|}{$5-\mathrm{HT}(\mu \mathrm{g} / \mathrm{kg})$} \\
\hline & & 5 & 10 & 20 & 40 & 80 \\
\hline $\begin{array}{l}\text { Control } \\
\text { Hexamethonium }\end{array}$ & 6 & $\begin{array}{l}13.8 \pm 6.6^{\circ} \\
11.6 \pm 4.7\end{array}$ & $\begin{array}{l}14.6 \pm 5.2 \\
13.6 \pm 4.3\end{array}$ & $\begin{array}{l}19.4 \pm 7.8 \\
17.8 \pm 6.8\end{array}$ & $\begin{array}{l}28.6 \pm 12.9 \\
21.2 \pm 4.9\end{array}$ & $\begin{array}{l}32.0 \pm 14.5 \\
26.6 \pm 11.0\end{array}$ \\
\hline $\begin{array}{l}\text { Control } \\
\text { Phentolaminet }\end{array}$ & 5 & $\begin{array}{l}15.8 \pm 5.3 \\
15.6 \pm 6.8\end{array}$ & $\begin{array}{l}37.0 \pm 8.6 \\
26.0 \pm 7.5\end{array}$ & $\begin{array}{l}53.0 \pm 13.0 \\
43.0 \pm 10.3\end{array}$ & $\begin{array}{l}63.8 \pm 13.0 \\
60.0 \pm 13.0\end{array}$ & $\begin{array}{l}68.0 \pm 14.0 \\
75.0 \pm 27.0\end{array}$ \\
\hline $\begin{array}{l}\text { Control } \\
\text { Propranololt }\end{array}$ & 6 & $\begin{array}{l}-6.0 \pm 2.1 \\
-2.0 \pm 1.4\end{array}$ & $\begin{array}{l}-19.2 \pm 8.3 \\
-16.3 \pm 6.7\end{array}$ & $\begin{array}{l}-21.2 \pm 7.9 \\
-18.0 \pm 6.5\end{array}$ & $\begin{array}{l}-23.7 \pm 7.5 \\
-21.7 \pm 6.2\end{array}$ & $\begin{array}{l}-23.7 \pm 7.5 \\
-22.3 \pm 6.0\end{array}$ \\
\hline
\end{tabular}

- Values are means $\pm \mathrm{SE}$ of changes $(\Delta)$ in the amplitude of phasic contractions in $\mathrm{mmHg}$ before and after antagonists.

† Paired Student's $t$ test comparing $\Delta$ pressure induced by 5 - HT in the control state and after treatment were not significantly different. The symbol $(-)$ refers to $\Delta$ SO relaxation in response to 5 -HT. 


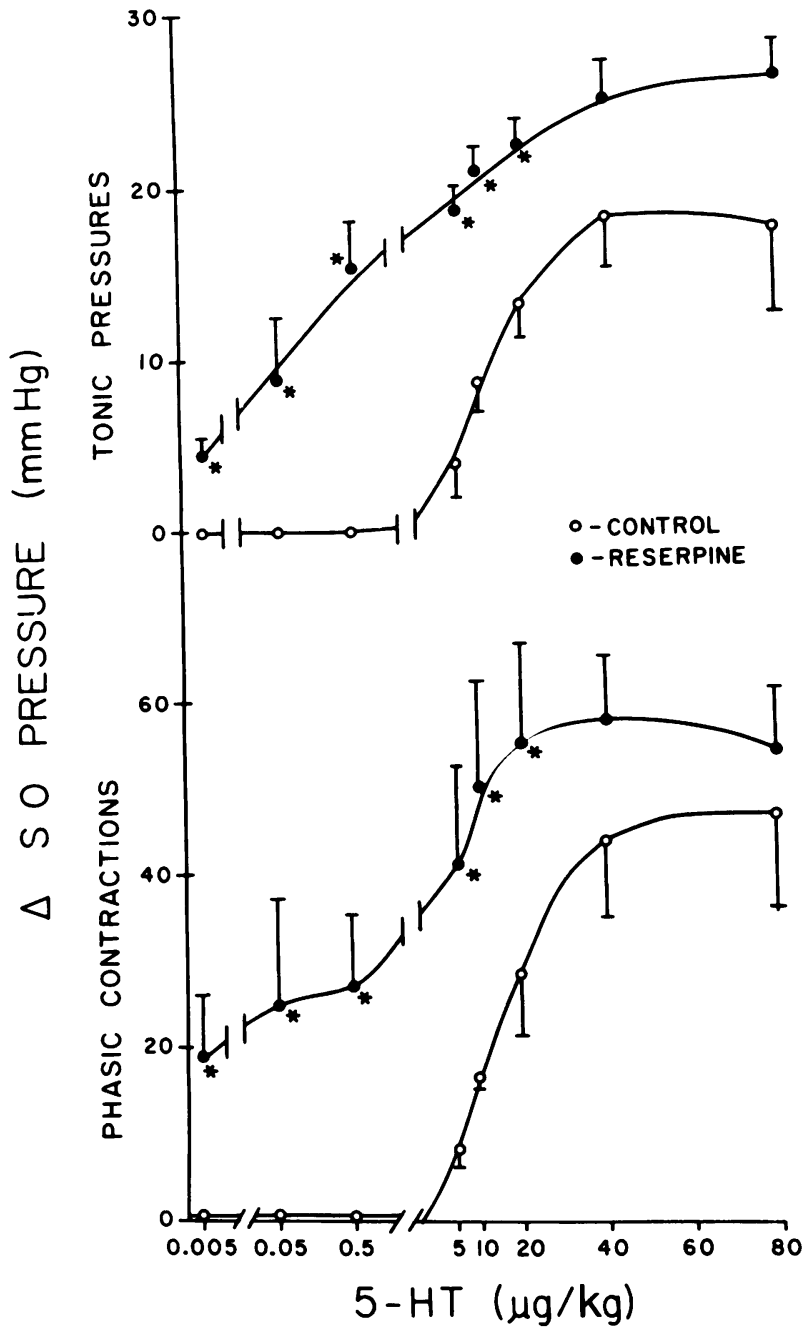

Figure 8 Effect of pretreatment with reserpine on the SO contraction induced by 5-HT. Values are means $\pm S E$ of four reserpinized animals and of five control animals. Asterisks indicate when the 5-HT effect on the SO in reserpine-treated animals was significantly different from that of control animals $(P<0.01)$. $P$ values were obtained with an unpaired Student's $t$ test.

\section{DISCUSSION}

5-HT activates several receptors in the cat SO. Stimulation of these diverse receptors may explain the variable SO motor response to exogenous 5-HT (11). The net SO response results from the algebraic sum of the effects mediated by these receptors in each individual animal. Irrespective of the initial type of SO motor response, however, blocking one or more receptors uncovers others, either excitatory or inhibitory, that were not apparent in the initial response. Thus, pharmacological manipulation makes it possible to change

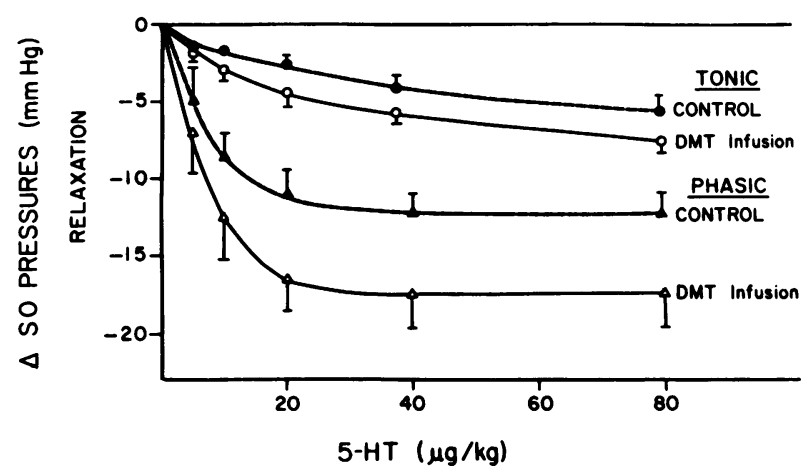

Figure 9 Dose-response studies with 5-HT before and during a constant infusion of 5-Me-DMT. Values are means \pm SE of the SO relaxation in response to $5-\mathrm{HT}$ in six animals.

an SO contraction to relaxation and vice versa. These findings are in agreement with previous studies that have demonstrated multiple 5 -HT receptors in the gastrointestinal tract, both at muscular and at neural sites (3).

Complete blockade of axonal transmission with TTX did not impair the net contraction, but it completely antagonized the relaxation induced by $5-\mathrm{HT}$. These findings suggest that 5-HT has a direct excitatory effect on the SO circular smooth muscle. In contrast, the 5-HT-induced contraction was blocked partially by atropine and was not affected by hexamethonium; this suggested the existence of a second excitatory 5-HT receptor present on postganglionic cholinergic neurons. Previous studies have shown that 5-HT can either stimulate or inhibit the release of acetylcholine (1214). Our findings support the hypothesis that 5-HT stimulated the release of acetylcholine in the cat SO.

The 5-HT smooth muscle excitatory receptor was sensitive to a 5-HT analogue, methysergide (15). Methysergide antagonized partially the SO contraction. After pretreatment with either atropine or TTX, however, it blocked it completely. The partial antagonism by atropine and methysergide, however, are different. Methysergide only antagonized the action of lower doses of 5-HT, which suggested competitive inhibition; atropine blocked partially the effect of all doses of 5HT, which suggested noncompetitive mechanisms. The findings that a combination of atropine and methysergide completely blocks the 5-HT-induced contraction further supports the existence of two separate receptors for 5-HT; one on the postganglionic cholinergic neurons and the other on the smooth muscle of the SO.

The difference between the effect of atropine, which partially blocks the excitatory SO response to 5-HT, and of TTX, which does not, could be due to one of two mechanisms. Most likely, TTX blocks 5-HT stim- 
TABLE II

Effect of Pharmacological Antagonists on Basal SO Motor Activity

\begin{tabular}{|c|c|c|c|c|c|}
\hline & $n^{\bullet}$ & $\begin{array}{c}\text { Tonic } \\
\text { pressures }\end{array}$ & $P<\$$ & $\begin{array}{c}\text { Phasic } \\
\text { contractions }\end{array}$ & $P<\$$ \\
\hline & & $m m H g$ & & $m m H g$ & \\
\hline $\begin{array}{l}\text { Control } \\
\text { TTX }\end{array}$ & 8 & $\begin{array}{l}14.4 \pm 1.7 \ddagger \\
20.8 \pm 2.2\end{array}$ & 0.004 & $\begin{array}{l}12.6 \pm 1.0 \\
18.4 \pm 1.5\end{array}$ & 0.001 \\
\hline $\begin{array}{l}\text { Control } \\
\text { Atropine }\end{array}$ & 8 & $\begin{array}{l}16.4 \pm 1.6 \\
14.5 \pm 1.8\end{array}$ & 0.10 & $\begin{array}{l}16.8 \pm 2.3 \\
11.3 \pm 1.8\end{array}$ & 0.005 \\
\hline $\begin{array}{l}\text { Control } \\
\text { Methysergide }\end{array}$ & 6 & $\begin{array}{l}16.3 \pm 2.4 \\
15.2 \pm 1.7\end{array}$ & 0.5 & $\begin{array}{l}17.2 \pm 1.0 \\
11.8 \pm 0.8\end{array}$ & 0.05 \\
\hline $\begin{array}{l}\text { Control } \\
\text { Atropine and } \\
\text { methysergide }\end{array}$ & 7 & $\begin{array}{l}15.3 \pm 1.4 \\
10.7 \pm 0.8\end{array}$ & 0.005 & $\begin{array}{r}13.9 \pm 1.3 \\
5.3 \pm 0.3\end{array}$ & 0.005 \\
\hline $\begin{array}{l}\text { Control } \\
\text { 5-HT Tachyphylaxis } \\
\text { TTX }\end{array}$ & $\begin{array}{l}6 \\
6\end{array}$ & $\begin{array}{r}17.3 \pm 2.5 \\
8.3 \pm 2.5 \\
21.0 \pm 1.9\end{array}$ & $\begin{array}{l}0.001 \\
0.001\end{array}$ & $\begin{array}{c}35.8 \pm 14.2 \\
7.5 \pm 3.8 \\
27.0 \pm 6.2\end{array}$ & $\begin{array}{l}0.05 \\
0.001\end{array}$ \\
\hline $\begin{array}{l}\text { Control } \\
\text { Hexamethonium }\end{array}$ & 5 & $\begin{array}{l}11.3 \pm 1.3 \\
14.3 \pm 2.1\end{array}$ & 0.10 & $\begin{array}{l}11.0 \pm 1.8 \\
13.8 \pm 2.4\end{array}$ & 0.10 \\
\hline $\begin{array}{l}\text { Control } \\
\text { Phentolamine }\end{array}$ & 6 & $\begin{array}{l}17.8 \pm 2.6 \\
16.8 \pm 2.5\end{array}$ & 0.70 & $\begin{array}{l}13.3 \pm 3.8 \\
10.0 \pm 2.5\end{array}$ & 0.30 \\
\hline $\begin{array}{l}\text { Control } \\
\text { Propranolol }\end{array}$ & 6 & $\begin{array}{l}18.3 \pm 2.8 \\
20.0 \pm 2.6\end{array}$ & 0.50 & $\begin{array}{l}16.3 \pm 1.8 \\
20.8 \pm 2.4\end{array}$ & 0.08 \\
\hline $\begin{array}{l}\text { Control } \\
\text { Reserpine }\end{array}$ & $\begin{array}{l}15 \\
10\end{array}$ & $\begin{array}{r}12.8 \pm 0.8 \\
4.9 \pm 1.1\end{array}$ & 0.001 & $\begin{array}{r}28.0 \pm 4.1 \\
4.1 \pm 1.4\end{array}$ & 0.001 \\
\hline
\end{tabular}

ulation of both excitatory, postganglionic cholinergic and nonadrenergic, noncholinergic inhibitory neurons. The elimination of the inhibitory component of the SO response may compensate for the loss of the cholinergic excitatory component and result in an apparently unaffected net SO contraction. Alternatively, by blocking basal activity of serotonergic neurons and preventing the release of endogenous 5-HT, TTX may increase the number of available 5-HT receptors, and thus make the SO smooth muscle supersensitive to exogenous 5-HT. This supersensitivity may compensate for the loss of the postganglionic cholinergic excitatory component to the SO, which is also blocked by TTX. These 5-HT excitatory receptors appear to be specific as demonstrated in experiments with tachyphylaxis (16). Large dose of 5-HT caused tachyphylaxis for itself, but did not affect the SO response to other excitatory drugs, such as bethanechol.

Pretreatment with reserpine increased the magnitude of the SO contraction in response to 5-HT, which shifted the dose-response curve to the left without affecting the 5-HT-induced relaxation. The reserpinetreated SO responded to doses of 5-HT a thousand times smaller than needed to excite the SO in control conditions. These findings can be explained by some of the known effects of reserpine in the gastrointestinal tract. It is likely that the SO supersensitivity is due to 5-HT depletion. Serotonergic neurons have been found throughout the myenteric plexus of the gastrointestinal tract $(3,17)$. We also have indirect evidence that they are present in the SO myenteric plexus (18). Thus, it is conceivable that reserpine may make excitatory neural and muscle receptors available for stimulation by exogenous 5 -HT. Alternative explanations are also possible. The possibility that catecholamine depletion may cause increased sensitivity to 5 -HT is unlikely because adrenergic neurons or alpha adrenergic receptors do not mediate the actions of 5-HT. SO supersensitivity to 5-HT could result from increased cholinergic activity, which has been observed in re- 
serpine-treated guinea pig ileum (19). This mechanism, however, was not explored.

The 5-HT-induced SO relaxation was antagonized only by TTX and 5-HT tachyphylaxis, which suggests that it was due to a neurally mediated action with a specific receptor for 5-HT. The finding that hexamethonium failed to block this effect suggests that it is not due to inhibition of presynaptic release of acetylcholine at ganglionic levels as some previous studies have suggested (14). More likely this 5-HT inhibitory effect is the result of stimulation of noncholinergic, nonadrenergic inhibitory neurons. Their presence in the SO myenteric plexus has been suggested by pharmacological studies with cholecystokinin, which relaxes the SO by stimulating these neurons (10). Other studies also have indicated that 5-HT stimulates these nonadrenergic, noncholinergic inhibitory neurons that participate in the peristaltic reflex that results in relaxation of the distal intestinal segment $(20,21)$ and in the vagal inhibitory pathway that causes relaxation of the fundus of the stomach (22) and lower esophageal sphincter (23). It has been suggested that 5-Me-DMT is a selective 5-HT antagonist acting at receptors located in these inhibitory neurons (24). However, these inhibitory actions of 5-HT in the SO were not blocked by any of the selective 5-HT antagonists used, despite the specificity of the 5-HT receptors. Other antagonists also have failed to block the 5-HT neural receptors in the gastrointestinal tract $(16,25)$. The lack of a selective antagonist for the inhibitory receptors prevented us from assessing their physiological role, if any, on the SO motor function.

SO denervation results in an increase in SO motor activity. TTX, however, has no direct effect on smooth muscle contraction $(26,27)$. These findings suggest that basal SO motor activity is myogenic in origin and regulated by neural mechanisms. By blocking axonal transmission, TTX eliminated all excitatory and inhibitory neural effects, which released the SO smooth muscle from a predominant inhibitory influence. The TTX effect, however, contrasted markedly with the action of 5-HT antagonists or 5-HT depletion, which caused a decrease in SO motor activity. This discrepancy can be best explained by the existence of two parallel but opposing neural pathways, one excitatory and the other inhibitory. Partial blockade of this pathway with either atropine or methysergide resulted in a moderate decrease in SO motor activity due to an increase in the imbalance between excitatory and inhibitory pathways. Complete blockade of excitatory, serotonergic, postganglionic cholinergic pathways by a combination of atropine and methysergide, 5-HT tachyphylaxis, or 5-HT depletion with reserpine caused a greater decrease in SO motor activity; this was probably due to an unopposed activity of the inhibitory neurons. These conclusions are further supported by the finding that the decrease in basal SO motor activity after 5-HT tachyphylaxis was reversible after the SO was denervated by TTX. The specific contribution of the inhibitory neurons to basal SO motor activity could not be evaluated because they could not be selectively blocked since the nature of their neurotransmitter is unknown.

In summary, the present studies have shown that 5HT caused an initial contraction with an increase in tonic pressures and the amplitude of phasic contractions, which was followed by a more prolonged relaxation; it also could cause an exclusive relaxation with a reduction in tonic pressures and abolition of phasic contractions. The 5-HT-induced contraction appeared to be mediated by receptors present on the postganglionic cholinergic neurons and on the smooth muscle of the SO. These cholinergic and serotonergic neurons appeared to participate in the control of the SO motor activity because the administration of atropine and methysergide, 5-HT tachyphylaxis, and reserpine produced a significant reduction in basal SO motor activity. These findings also suggest that serotonergic neurons were not only interneurons innervating postganglionic cholinergic neurons, but that they also innervated the SO smooth muscle fibers by stimulating them directly. The relaxation induced by 5-HT appeared to be mediated by specific receptors present at noncholinergic, nonadrenergic inhibitory neurons because it could not be antagonized by any blocker except for TTX and 5-HT tachyphylaxis. The excitatory effect appeared to be a physiological action of 5-HT, whereas the role of the inhibitory action remains unclear.

\section{ACKNOWLEDGMENTS}

The authors would like to thank Carol Marin and Susan Field for their invaluable laboratory assistance, and Lorie Klemer for her secretarial help.

\section{REFERENCES}

1. Costa, M., and J. B. Furness. 1979. Commentary: on the possibility that an indoleamine is a neurotransmitter in the gastrointestinal tract. Biochem. Pharmacol. 28:565571 .

2. Gershon, M. D. 1979. Putative neurotransmitters: serotonin. Neurosci. Res. Program Bull. 17:414-424.

3. Gershon, M. D., and S. M. Erde. 1981. The nervous system of the gut. Gastroenterology. 80:1571-1594.

4. Feldberg, W., and C. C. Toh. 1953. Distribution of 5hydroxytryptamine (serotonin, enteramine) in the wall of the digestive tract. J. Physiol. (Lond.). 119:352-362.

5. Gershon, M. D., and H. Tamir. 1980. Serotonin binding protein: role in transmitter storage in central and peripheral serotonergic neurons. In Serotonin. B. Haber, editor. Plenum Publishing Co., New York.

6. Gershon, M. D., R. G. Robinson, and L. L. Ross. 1976. 
Serotonin accumulation in the guinea-pig myenteric plexus: ion dependence, structure-activity relationship and the effect of drugs. J. Pharmacol. Exp. Ther. 198:548-561.

7. Dingledine, R., A. Goldstein, and J. Kendig. 1974. Effects of narcotic opiates and serotonin on the electrical behavior of neurons in the guinea pig myenteric plexus. Life Sci. 14:2299-2309.

8. Jonakait, G. M., H. Tamir, A. R. Gintzler, and M. D. Gershon. 1979. Release of ${ }^{3} \mathrm{H}$-serotonin and its binding protein from enteric neurons. Brain Res. 174:55-69.

9. Dingledine, R., and A. Goldstein. 1976. Effect of synaptic transmission blockade on morphine action in the guinea pig myenteric plexus. J. Pharmacol. Exp. Ther. 196:97-106.

10. Behar, J., and P. Biancani. 1980. Effect of cholecystokinin and the octapeptide of cholecystokinin on the feline sphincter of Oddi and gallbladder. J. Clin. Invest. 66:1231-1239.

11. Johnson, S. M., Y. Katayama, and R. A. North. 1980 Multiple actions of 5-hydroxytryptamine on myenteric neurones of the guinea-pig ileum. J. Physiol. (Lond.). 304:459-470.

12. Costa, M., and J. B. Furness. 1979. The sites of action of 5-hydroxytryptamine in nerve-muscle preparations from the guinea-pig small intestine and colon. $\mathrm{Br} . J$. Pharmacol. 65:237-248.

13. Rattan, S., and R. K. Goyal. 1977. Effects of 5-hydroxytryptamine on the lower esophageal sphincter in vivo. Evidence for multiple sites of action. J. Clin. Invest. 59:125-133.

14. North, R. A., G. Henderson, Y. Katayama, and S. M. Johnson. 1980. Electrophysiological evidence for presynaptic inhibition of acetylcholine release by 5-hydroxytryptamine in the enteric nervous system. Neuroscience. 5:581-586.

15. Gyermek, L. 1961. 5-hydroxytryptamine antagonists. Pharmacol. Rev. 13:399-439.

16. Burks, T. F. 1981. Actions of drugs on gastrointestinal motility. In Physiology of the GI Tract. L. R. Johnson, editor. Raven Press, New York. 495-516.

17. Burks, T. F. 1973. Mediation by 5-hydroxytryptamine of morphine stimulant actions in dog intestine. J. Pharmacol. Exp. Ther. 185:530-539.

18. Behar, J., and P. Biancani. 1982. Effect of naloxone on the cat sphincter of Oddi (SO): evidence for a physiological role of opioid peptides in the regulation of the sphincter of Oddi. In Proceedings of the 8th International Symposium on Gastrointestinal Motility. Raven Press, New York. 397-403.

19. Green, R. D., W. W. Fleming, and J. L. Schmidt. 1968. Sensitivity changes in the isolated ileum of the guinea pig after pretreatment with reserpine. J. Pharmacol. Exp. Ther. 162:270-276.

20. Costa, M., and J. B. Furness. 1976. The peristaltic reflex: an analysis of the nerve pathways and their pharmacology. Naunyn-Schmiedeberg's Arch. Pharmacol. 294:47-60.

21. Jule, Y. 1980. Nerve-mediated descending inhibition of the proximal colon of the rabbit. J. Physiol. (Lond.). 159:361-380.

22. Bulbring, E., and M. D. Gershon. 1968. Serotonin participation in the vagal inhibitory pathway to the stomach. Adv. Pharmacol. 6A:323-333.

23. Rattan, S., and R. K. Goyal. 1978. Evidence of 5-HT participation in vagal inhibitory pathway to opossum LES. Am. J. Physiol. 234:E273-E276.

24. Gessner, P. K. 1969. Pharmacological studies of 5-methoxy- $N, N$-dimethyltryptamine, LSD, and other hallucinogens. In Psychosomatic Drugs. D. H. Efron, editor. Raven Press, New York. 105-122.

25. Drakontides, A. B., and M. D. Gershon. 1968. 5-HT receptors in the mouse duodenum. Br. J. Pharmacol. 33:480-492.

26. Kao, C. Y. 1972. Pharmacology of tetrodotoxin and saxitoxin. Fed. Proc. 31:1117-1123.

27. Gershon, M. D. 1967. Effects of tetrodotoxin on innervated smooth muscle preparations. $\mathrm{Br}$. J. Pharmacol. Chemother. 29:259-279. 